\title{
Liam Smeeth: Still hoping for Olympic gold
}

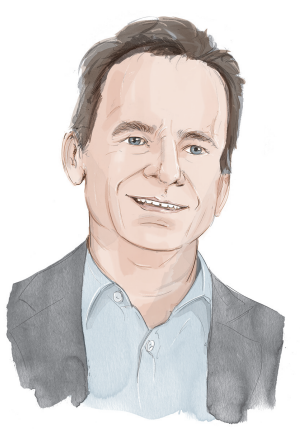

What was your earliest ambition?

To kiss Rebecca (unfulfilled).

\section{Who has been your biggest inspiration?}

My dad. When I was growing up, caring for others, acting with integrity, and treating people equally weren't optional: they were just things you did, like breathing or walking.

\section{What was the worst mistake in your career?}

My medical house job was pretty grim. I was the last of the generation to do 100 hour weeks, although I fear I'm in danger of romanticising what a great training this provided.

\section{What was your best career move?}

Doing the MSc in epidemiology at the London School of Hygiene and Topical Medicine. On the first morning I sat down between a woman from Chad who had just completed medical training in Moscow, who cheerfully told me that learning Russian wasn't as big a challenge as being a lesbian in Russia, and a Belgian woman who had just come back from caring for people with cholera in the refugee camps in Rwanda. I felt at home in the world.

\section{Bevan or Lansley? Who has been the best and the worst health secretary in your lifetime?}

Bevan founded the NHS! Has anyone in the history of this column ever chosen Lansley over Bevan? Ever?

\section{Who is the person you would most like to thank and why?}

My mother, who I don't remember at all. She died when I was 3.

\section{To whom would you most like to apologise?}

My dad. I was an unappreciative 18 year old when he died.

\section{If you were given $£ 1 \mathrm{~m}$ what would you spend it on?}

I'd share it out to family and to charities that campaign for a better world, such as Amnesty International and Shelter.

\section{Where are or were you happiest?}

Last time I had sex (weirdly, no one seems to mention sex in this column, so if that's unsuitable the answer "Here and now" will do).

What single unheralded change has made the most difference in your field in your lifetime?

Apologies for such a dull answer, but computers have revolutionised healthcare and research in high income settings.

\section{Do you support doctor assisted suicide?}

In theory yes, but in practice no. It's easy to see mistakes being made, and there's no going back. For example, 20 years ago in the West-and today in low income settings-many people would have opted for suicide when what they needed was good pain relief or adequate treatment for depression.

\section{What book should every doctor read?}

No relation to being a doctor, but my favourites include Jasmine by Bharati Mukherjee, Requiem for the East by Andrei Makine, and Ahab's Wife by Sena Jeter Naslund. They are loosely all about the central goodness of humans in a difficult and changing world. 
Biography

Liam Smeeth is professor of clinical epidemiology at the London School of Hygiene and Tropical Medicine. His interest in the causes of disease and the evidence base for its treatment was triggered by wondering about the evidence behind his advice to patients as a GP. One of his first studies helped to refute the link between the MMR vaccination and autism by using general practice records, and he is an enthusiast for the value of linking big data for the better understanding of disease.

What poem, song, or passage of prose would you like mourners at your funeral to hear?

I hope that they'll be celebrating, not mourning.

\section{What is your guiltiest pleasure?}

Sitting on a ski lift in the sunshine with my daughters.

If you could be invisible for a day what would you do?

That is too weird an idea: it would be just like stalking people.

\section{What television programmes do you like?}

Made in Chelsea, although I often catch the last 10 minutes of Nordic noir thriller episodes. The West Wing was the best thing I've ever seen.

What is your most treasured possession? My bike.

\section{What, if anything, are you doing to reduce your carbon footprint?}

Going most places by bike, although Brazil defeated me.

\section{What personal ambition do you still have?}

Olympic gold medal in the decathlon.
Summarise your personality in three words

One word from each of my children: weird; whatever; fantastic (possibly said with irony).

\section{Where does alcohol fit into your life?}

Comfortably, in the evenings.

\section{What is your pet hate?}

Ketchup.

What would be on the menu for your last supper?

Anything good quality and well cooked. The company and being outdoors would matter far more than the food.

Do you have any regrets about becoming a doctor?

None.

\section{If you weren't in your present position} what would you be doing instead?

A career in intensive care briefly appealed, but I'd probably just be winning an Olympic gold medal in the decathlon.

Cite this as: BMJ 2015;351:h5097

๑ BMJ Publishing Group Ltd 2015 